\title{
Electrical Properties of Silicone Rubber Filled with Surface Treated Alumina Trihydrate
}

\author{
Se-Young Jung ${ }^{\mathrm{a}}$ and Byung-Kyu Kim \\ Department of Polymer Science and Engineering, Pusan National University, \\ Jangjeon 2-dong, Geumjeong-gu, Pusan 609-735, Korea \\ ${ }^{a}$ E-mail : polyster@pusan.ac.kr
}

(Received March 31 2006, Accepted May 18 2006)

\begin{abstract}
The effect of surface treatment of fillers on the mechanical, electrical properties, and tracking performance of silicone rubber insulators have been investigated. For base polymer, $\alpha, \omega$ vinyl poly(dimethyl-methylphenyl) siloxane(VPMPS) containing dimethyl siloxane and methylphenyl siloxane was prepared by the equilibrium polymerization. High voltage silicone rubber composites(HVSRC) were prepared from VPMPS, nano-silica, and alumina trihydrate (ATH) modified by various coupling agents. Bound rubber of uncured silicone rubber, crosslinking density of the vulcanizate as well as the mechanical, electrical properties, and tracking performance were measured.
\end{abstract}

Keywords : High voltage silicone rubber composites(HVSRC), Alumina trihydrate(ATH), Surface treatment, Coupling agents, Tracking performance

\section{INTRODUCTION}

During the 1930s, extensive researches on silicone chemistry have been carried out and Rochow discorvered the "Direct Process" for the production of chlorosilanes which enabled the economical production of silicone[1-4]. Silicone is a most widely used polymer in adhesive, coating, and rubber materials in the electronic circuits of microelectronic devices. Because silicone polymers used in preparing silicone rubber compositions include inorganic and organic portions and these provide silicon rubber with excellent weather and thermal stability, oxidation resistance, good electrical properties, extreme low- temperature flexibility, and curability by a various methods at both elevated and ambient temperature[5,6].

In recent years, the polymer insulator have been increasingly used for outdoor high voltage insulation since they have some advantages while compared with the ceramic insulator, such as light weight, low cost, and good contamination performance[7-11]. The silicone rubber has good weatherbility, thermal stability, electric properties and surface hydrophobicity.

But the high voltage insulator (HVI) silicone rubber composite was filled with high amount alumina trihydrate(ATH) for improving the tracking performance of silicone rubber.
It weakened the mechanical properties of HVI silicone rubber composite. So, the tracking and mechanical properties are the biggest problems to be overcome simultaneously in high voltage silicone rubber composite. In this paper, for improving tracking properties and heat stability, $\alpha, \omega$-Vinyl poly(dimethyl-methylphenyl) siloxane prepolymer (VPMPS) was prepared by the equilibrium polymerization of Octamethylcyclo tetrasiloxane (D4), '1,3,5-trimethylphenylcyclo trisiloxane (D3 Me,Ph), and 1,3-divinyl- 1,3-tetramethyl-siloxane (VMS) as end-blocker. And also, HVI silicone rubber composite containing surface treated ATH modified by various coupling agents was prepared by compounding VPMPS, surface treated ATH, and catalyst in high speed kneader, and we have investigated the influence of surface treatment of fillers on the mechanical and electrical properties, and tracking performance of silicone rubber insulator.

\section{EXPERIMENT}

\subsection{Materials and reagents}

1,3-Divinyl-1,3-tetramethyldisiloxane(VMS), 1,3,5triphenylmethylcyclotrisiloxane (D $3^{\mathrm{Me}, \mathrm{Ph}}$ ) and octamethylcyclotetrasiloxane (D4) were supplied from Aldrich and Bayer.

3-Methacryloxypropyl triethoxysilane(AES), vinyltriethoxylsilane(VES), and strearic acid(SA) were supplied 
from Shin-Etsu. All materials were stroed in a refrigenator and used without further purification. Tetramethyl-ammonium siloxanolate (TMAS) used as catalyst was prepared from reactions between hexamethylcyclo trisiloxane(D3) and tetramethylammonium hydroxide(TMAH) purchased from Fluka. Nanosilica with $200 \mathrm{~m}^{2} / \mathrm{g}$ of surface and $80 \sim 100 \mathrm{~nm}$ of particle size was supplied from Degussa. ATH(SF-4) was supplied from Smitomo Co. 2, 5-Dimethyl 2,5-t-butyl peroxy hexane(DMTBPH) used as cross-linking agent was supplied from Aldrich.

2.2 Preparation of $\alpha$, $\omega$-vinyl poly(dimethylmethylphenyl) siloxane (VPMPS)

VPMPS was prepared using equilibrium polymerization according to McGrath method[12]. For example, in a four-necked flask equipped with a mechanical stirrer, reflux condenser, thermometer, and nitrogen inlet tube, D4, D3 ${ }^{\mathrm{Me}, \mathrm{Ph}}$ and VMS with a 1000:15:1 mole ratio were added, respectively and reacted for $4 \mathrm{~h}$ at $90{ }^{\circ} \mathrm{C}$, in the presence of $0.02 \mathrm{wt} \%$ of TMAS under nitrogen atmosphere. After completing the reaction, the reaction mixture was heated to $140{ }^{\circ} \mathrm{C}$ to decompose TMAS, and then vacuum stripped at 30 torr to remove oligomeric cyclic species and unreacted monomer (yield : $72 \%$ ).

\subsection{Preparation of high voltage silicone rubber} composite

High voltage silicone rubber composite was prepared from compounding of VPMPS, silica, and ATH modified with 3-methacryloxypropyl triethoxysilane (AES), vinyltriethoxylsilane (VES), and strearic acid (SA) according to formulation shown in Table 1. using a kneading machine (Linden Co. Model KII 10) at $180^{\circ} \mathrm{C}$ for 8 hours. Test specimen were prepared from compression mold with DMTBPH at $175{ }^{\circ} \mathrm{C}$ for 10 minutes under $15 \mathrm{MPa}$ pressure.

\subsection{Characterizations}

2.4.1 Instrumental analysis

FT-IR spectra were obtained from Perkin Elmer Spectrum GX FT-IR Spectrometer. ${ }^{13} \mathrm{C}-\mathrm{NMR}$ and ${ }^{1} \mathrm{H}-$ NMR spectra were obtained from Variann EM-360 NMR for polymer solution in $\mathrm{CDCl}_{3}$ solution. Tetramethylsilane(TMS) was used as an internal reference. Thermal stability of HVSRC was evaluated by TG analysis (Seiko Company TG/DTA EXTRA 6000). TG graphs were obtained. Cross-linking density of HVSRC was measured at $110^{\circ} \mathrm{C}$ using Monsanto Oscillation Disk Cure Meter(Model : ODR 100) according to ASTM D 2084. Mechanical Properties were measured at room temperature using Instron Universal Testing Machine Model 4411 according to ASTM D 412 and 624. Flame retardant was measured according to UL $94 \mathrm{~V}$ method[13].

\subsubsection{Tracking characteristic test}

Tracking resistance was referred to IEC 60587 but the concentration of conductive material was twice of IEC standard in order to accelerate the tracking failure[14]. Examination circuit diagram of IEC 60587 standards and experimental condition used in this experiments are shown in Table 2 .

\subsubsection{Measurement of the bound rubber content}

The extraction method was adopted to measure bound rubber content in uncured HVSRC[15]. About $10 \mathrm{~g}$ of uncured HVSRC was precisely weighed and wrapped with filter paper. The wrap was immersed in pure toluene of $100 \mathrm{~cm}^{3}$. at room temperature for 7 days. After 7 days, the warp was dried and weighed.

The bound rubber (BR) content in the uncured HVSRC was calculated according to the following equation(1):[16].

Table 1. Formulation of high voltage silicone rubber composite.

(unit : phr)

\begin{tabular}{|c|c|c|c|c|c|}
\hline Ingredients & Samples & $\mathrm{SO}$ & SS & SA & SV \\
\hline \multicolumn{2}{|c|}{ VPMPS } & 100 & 100 & 100 & 100 \\
\hline \multicolumn{2}{|c|}{$A-200$} & 40 & 40 & 40 & 40 \\
\hline \multicolumn{2}{|c|}{ Process oil } & 2 & 2 & 2 & 2 \\
\hline \multicolumn{2}{|c|}{ ATH } & $20 \sim 100$ & $20 \sim 100$ & $20 \sim 100$ & $20 \sim 100$ \\
\hline \multirow{2}{*}{ Surface treatment } & Dosage $^{1)}$ & 0 & 2 & 2 & 2 \\
\hline & Coupling agent & non & stearic acid & acryl silane & vinyl silane \\
\hline
\end{tabular}

1) Amount of surface treatment agent is based on $100 \mathrm{phr}$ ATH. 
Table 2. Conditions of the tracking test.

\begin{tabular}{|c||c|}
\hline \multicolumn{1}{|c||}{ Item } & Contents \\
\hline \hline Applied voltage $(\mathrm{kV})$ & AC 4.5 \\
\hline Test specimen size $(\mathrm{mm})$ & $50 \times 120 \times 6$ \\
\hline Setting angle of specimen $\left({ }^{\circ}\right)$ & 45 \\
\hline Flow rate of contaminantst $(\mathrm{m} \ell / \mathrm{min})$ & 0.9 \\
\hline Series of resistance $(\mathrm{k} \Omega)$ & 33 \\
\hline Running time (hours) & 6 \\
\hline
\end{tabular}

$$
\mathrm{BR}=\frac{\left(\mathrm{M}_{\mathrm{B}}-\mathrm{M}_{\mathrm{F}}-\mathrm{M}_{\mathrm{D}}\right)}{\mathrm{M}_{\mathrm{B}}} \times 100 \%
$$

, where $M_{B}$ is the mass of the uncured HVSRC before immersing, $M_{F}$ is the mass of the filler in the uncured HVSRC which can be calculated from the formulation shown in Table $1, M_{D}$ is the mass of rubber dissolved in the organic solvent, which is equal to the difference between the mass of the uncured HVSRC before and after immersion.

\section{RESULTS AND DISCUSSION}

\subsection{Synthesis of VPMPS}

In the synthesis of vinyl end-blocked prepolymer containing the block unit of dimethylsiloxane and methylphenylsiloxane, TMAS attacks first $\mathrm{D} 3^{\mathrm{Me}, \mathrm{Ph}}$ with high ring strain, then dimethyl-siloxanecyclictetramer D4, and finally terminated with VMS. It is expected that the basic TMAS initiator will attack $\mathrm{D} 3^{\mathrm{Me}, \mathrm{ph}}$ with high ring strain first. The reaction mechanism for the preparation of VPMPS is shown in Scheme 1. The structure of VPMPS prepolymer was confirmed by the FTIR measurement (Fig. 1) and 13C-NMR(Fig. 2). The FT-TR spectra of VPMPS and HPDMS exhibited strong absorption peak at 1100 to $1020 \mathrm{~cm}^{-1}$ due to the $\mathrm{Si}-\mathrm{O}$ Si stretching vibration and at 1343 and $1613 \mathrm{~cm}^{-1}$ due to $\mathrm{Si}$-vinyl respectively. And the peaks due to $\mathrm{Si}-\mathrm{Ph}$ appeared at 1430,1892 , and $1961 \mathrm{~cm}^{-1}$. In the 13C-NMR spectrum of VPMPS the peaks due to Si-Ph appeared at $127.0 \sim 138.0 \mathrm{ppm}$ and at $0.867 \mathrm{ppm}$ due to Si-CH3.

Figure 3, shows TG thermograms of VPMPS and VMQ. It is found that the decomposition temperature of VPMPV is higher than that of VMQ. It means that thermal stability of VPMPS is improved by introducing phenyl group in siloxane polymer.

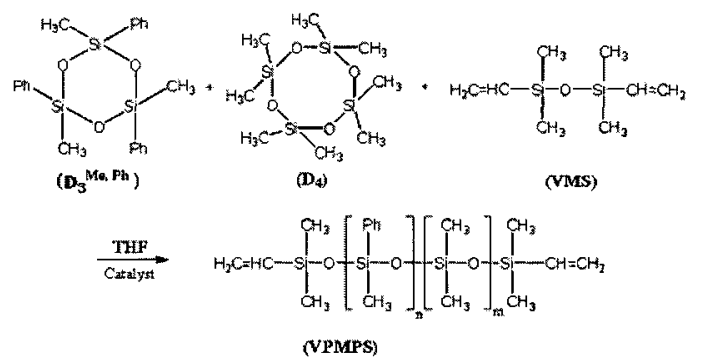

Scheme 1. Preparation of VPMPS.

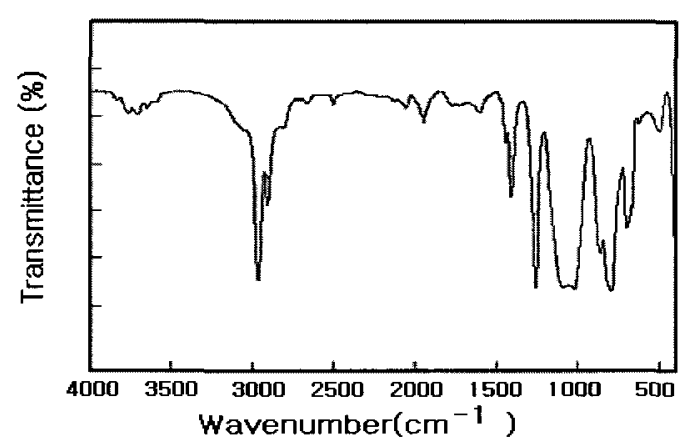

Fig. 1. FT-IR spectra for VPMPS.

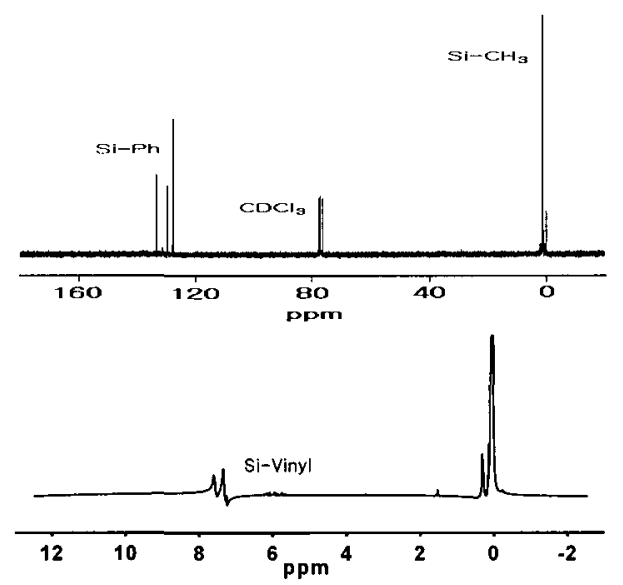

Fig. $2 .{ }^{13} \mathrm{C}-\mathrm{NMR}$ and ${ }^{1} \mathrm{H}-\mathrm{NMR}$ spectrum for VPMPS. 


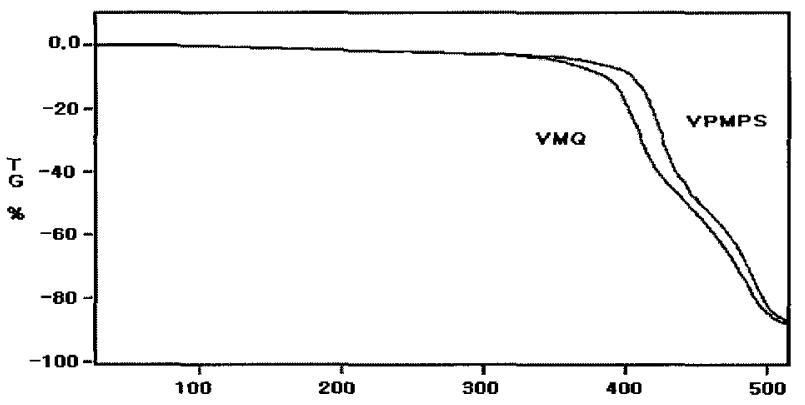

Fig. 3. Thermal properties of VPMPS and VMQ $(\alpha, \omega-$ vinyl polydimethyl siloxane).

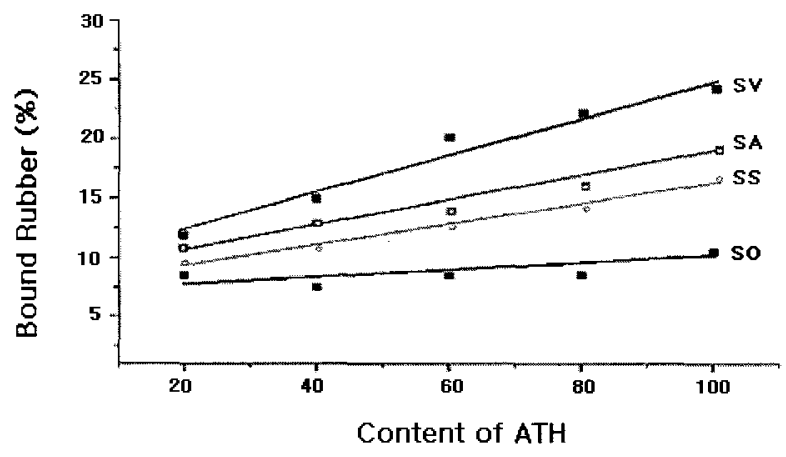

Fig. 4. Bound rubber contents of silicone compounds according to ATH treatment.

3.2 Properties of high voltage silicon rubber composite by ATH surface treatment

3.2.1 Bound rubber content

Bound rubber is the percentage of rubber that can no longer be separated from the filler when the rubber composite is extracted in a good rubber solvent such as toluene over a specific period of time, usually at room temperature. It reflects mainly chemical interactions between rubber and filler. In order to understand the influence of the surface modification of ATH, the bound rubber contents for different kinds of coupling agents were measured and the results are shown in Fig. 4. Bound rubber contents of the uncured HVSRC without coupling agent was below $10 \%$.

For the ATH surface treated with stearic acid, that of SS-100 containing 100 phr ATH was $14 \%$, and bound rubber content of SA-100 containing $100 \mathrm{phr}$ ATH treated with acryl silane was $16 \%$.

Bound rubber content of SV-100 containing $100 \mathrm{phr}$ ATH treatead with vinyl silane was $24 \%$. Vinyl group on the surface of ATH will react with rubber molecules or another ATH particle, resulting in an increase in bound rubber.

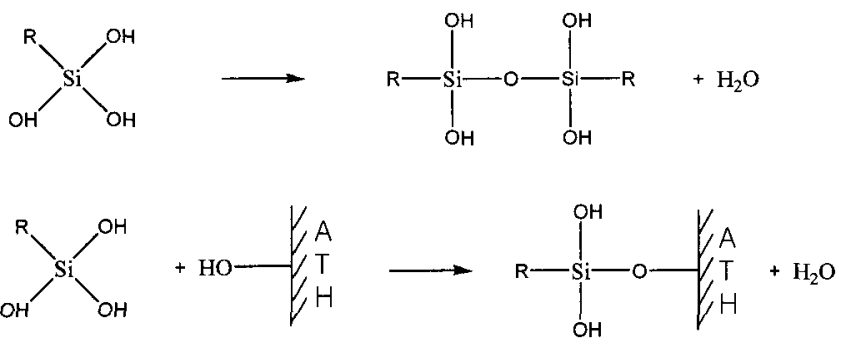

Scheme 2. Reaction mechanism of surface treatment.

\subsubsection{Cross-linking properties}

The cross-linking density of vulcanizate is the density of cross-linking between silicone polymer and ATH. The cross-linking is caused by chemical bonds, physical entanglements and embedding between silicone polymer and ATH.

Cross-linking properties according to the kinds of silane coupling were measured from oscillation disk meter and the results of HVSRC containing $100 \mathrm{phr}$ ATH is shown in Table 3. ATH treated with stearic acid, maximum torque of SS-100 is lower than $\mathrm{SO}-100$ containing 100 phr ATH without surface treatment. Stearic acid does not containing active groups and blocks off any active groups on the $\mathrm{ATH}$, which reduces chemical interaction and results in a decrease in crosslinking density. On the other hand, maximum torque of SV-100 containing $100 \mathrm{phr}$ ATH treated with vinyl silane showed the highest $(4.6 \mathrm{~N}-\mathrm{m})$. By reacting with hydroxy group on ATH, active groups are introduced on the surface of ATH. Therefore, active group $(-\mathrm{CH}=\mathrm{CH} 2)$ enhances chemical interactions and leads to an increase in cross-linking density.

The reaction mechanism of surface treatment is shown in Scheme 2. These results indicate that the surface treatment of ATH affects the interaction between ATH and silicone polymer, and bring about a change in the cross-linking density of silicone composite.

3.2.3 Mechanical and electrical properties of silicone rubber composite

Mechanical, electrical properties and tracking property of HVSRC according to coupling agent were measured and the results are shown in Table 3. As shown in Table 3 , the tensile strength of HVSRC SO without surface treatment is $4.1 \mathrm{MPa}$, and SV containing $100 \mathrm{phr} \mathrm{ATH}$ treated with vinyl silane is $5.8 \mathrm{MPa}$. Also, the hardness of SO is 70 (Shore A) and the hardness of SV containing ATH treated with vinyl silane is $7.5 \mathrm{MPa}$. The stressstrain curves of silicon rubber according to the kinds of surface treatment were measured and the results are shown in Fig. 5. 
Table 3. Mechanical properties comparison by ATH surface treatment.

\begin{tabular}{|c|c|c|c|c|}
\hline Type of Silane & $\begin{array}{l}\text { Without treatment } \\
\text { (SO) }\end{array}$ & $\begin{array}{c}\text { Stearic acid } \\
(\mathrm{SS})\end{array}$ & $\begin{array}{l}\text { Acryl silane } \\
\text { ( SA ) }\end{array}$ & $\begin{array}{l}\text { Vinyl silane } \\
\text { ( SV) }\end{array}$ \\
\hline $\begin{array}{l}\text { Density } \\
\left(\mathrm{g} / \mathrm{cm}^{3}\right)\end{array}$ & 1.50 & 1.50 & 1.50 & 1.50 \\
\hline $\begin{array}{l}\text { Hardness } \\
\text { (Shore A) }\end{array}$ & 70 & 57 & 68 & 76 \\
\hline $\begin{array}{l}\text { tensile strength } \\
\left(\mathrm{kgf} / \mathrm{cm}^{2}\right)\end{array}$ & 42 & 47 & 46 & 59 \\
\hline $\begin{array}{c}\text { Elongation } \\
(\%)\end{array}$ & 280 & 380 & 310 & 230 \\
\hline $\begin{array}{l}\text { Tear strength } \\
(\mathrm{kgf} / \mathrm{cm})\end{array}$ & 14 & 17 & 19 & 14 \\
\hline Bound Rubber (\%) & 8 & 16 & 19 & 24 \\
\hline Maximum Torque (N-m) & 4.03 & 2.91 & 3.45 & 4.6 \\
\hline $\begin{array}{c}\text { Volume resistivity } \\
(\Omega . \mathrm{cm})\end{array}$ & $1.0 \times 10^{14}$ & $1.8 \times 10^{14}$ & $2.2 \times 10^{12}$ & $14 \times 10^{14}$ \\
\hline $\begin{array}{l}\text { Dielectric breakdown strength } \\
(\mathrm{kV} / \mathrm{mm})\end{array}$ & 22 & 19 & 18 & 26 \\
\hline $\begin{array}{l}\text { Tracking } \\
\text { (minutes) }\end{array}$ & 370 & 390 & 370 & 490 \\
\hline
\end{tabular}

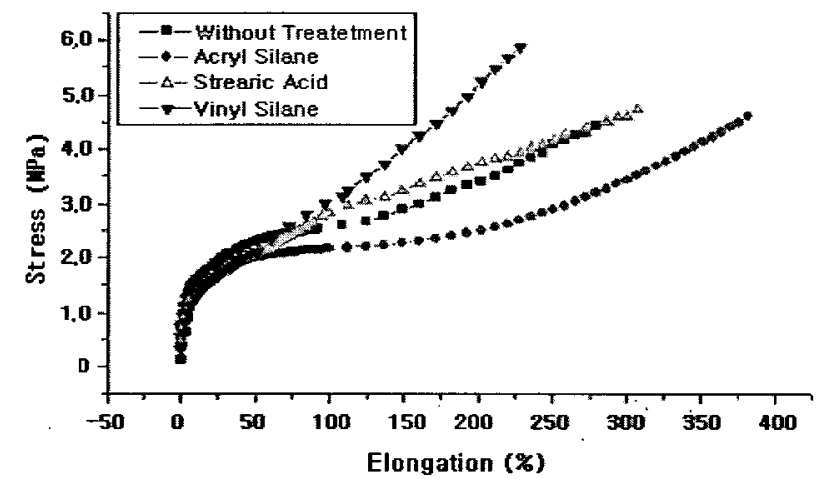

Fig. 5. The tensile behavior of silicone compound according to surface treatment.

Modulus of HVSRC containing ATH treated with stearic acid is lower than HVSRC filled with ATH without surface treatment. Stearic acid does not contain active groups and blocks off any active groups on the ATH, which reduces chemical interaction and results in a decrease in modulus. On the other hand, modulus of HVSRC containing $100 \mathrm{phr}$ ATH treated with vinyl silane showed the highest.

Active groups $(-\mathrm{CH}=\mathrm{CH} 2)$ introduced on the surface of ATH seem to enhance chemical interaction during and lead to an increase in modulus.

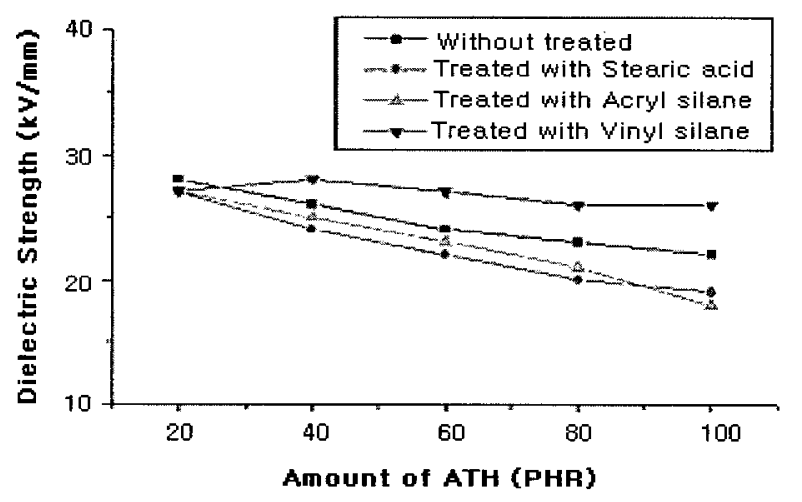

Fig. 6. Dielectric strength of silicone compounds according to surface treatment.

On the electrical properties, volume resistance of SO100 containing $100 \mathrm{phr}$ ATH without surface treatment decreases by $1 \times 10^{14} \Omega$.cm, volume resistance of SS- 100 containing ATH treated with stearic acid is $1.8 \times 10^{14}$ $\Omega . \mathrm{cm}$, volume resistance of SV-100 that containing 100 phr ATH treated with vinyl silane is the highest $\left(14 \times 10^{14}\right.$ $\Omega . \mathrm{cm})$. But volume resistance of electricity insulation material silicon rubber without ATH is very excellent insulation material $\left(1 \times 10^{16} \Omega . \mathrm{cm}\right)$. These results indicate that on increasing the content of ATH, volume resistivity of HVSRC decreases. Figure 6. shows dielectric break- 


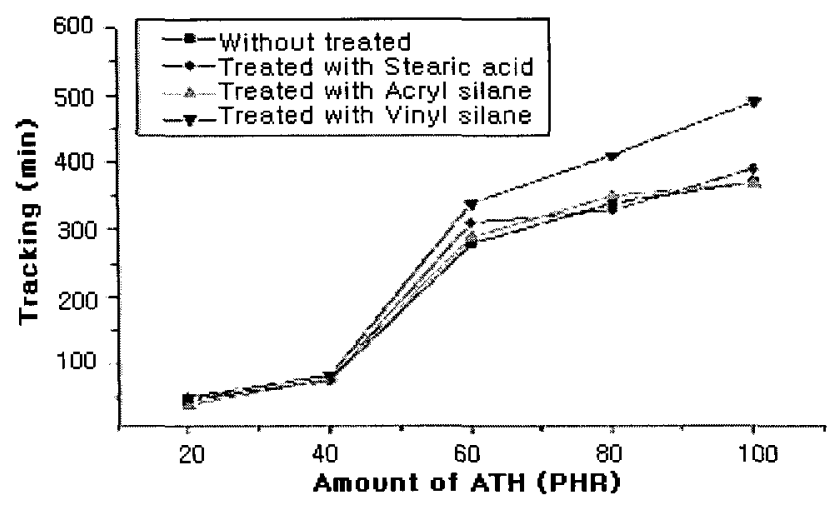

Fig. 7. Tracking resistance of silicone compound according to surface treatment.

down strength of HVSRC according to ATH content and ATH surface treatment. On increasing the content of ATH without surface treatment, treated with stearic acid, and treated with acryl silane, dielectric breakdown strength of these compound decreases.

On the other hand, dielectric breakdown strength of SV-100 filled with $100 \mathrm{phr}$ ATH treated with vinyl silane is $27 \mathrm{kV} / \mathrm{mm}$. Vinyl group introduced at the silica surface reacts with peroxide and cross-linking density increases. Therefore dielectric breakdown strength of $\mathrm{SV}-100$ is improved.

\subsubsection{Tracking and flame retardant characteristics}

Figure 7 and Fig. 8 show tracking characteristic and flame retardant characteristic of HVSRC according to ATH content and ATH surface treatment.

On increasing the content of $\mathrm{ATH}$, tracking and flame retardant are improved. Also when all compounds that were filled with $80 \mathrm{phr}$ of ATH satisfied IEC 60587 standard for tracking characteristics. And tracking and flame retardant characteristic of HVSRC filled with 100 ATH treated with vinyl silane are the highest $(490 \mathrm{~min}$ and $12 \mathrm{sec}$ ).

Increased cross-linking density by vinyl group introduced on the ATH surface is responsible for this.

\section{CONCLUSION}

For improving tracking properties and heat stability, $\alpha$, $\omega$ - Vinyl poly(dimethyl-methyl phenyl)siloxane prepolymer (VPMPS) was prepared by the equilibrium polymerization of octamethylcyclotetrasiloxane (D4), 1,3,5-trimethylphenylcyclotrisiloxane (D3 Me,Ph), and 1,3-divinyl- 1,3-tetramethyl-siloxane (VMS) as endblocker. And also, HVI silicone rubber composite containing surface treated ATH modified by various coupling agents was prepared by compounding VPMPS, surface treated ATH, and catalyst in high speed kneader.

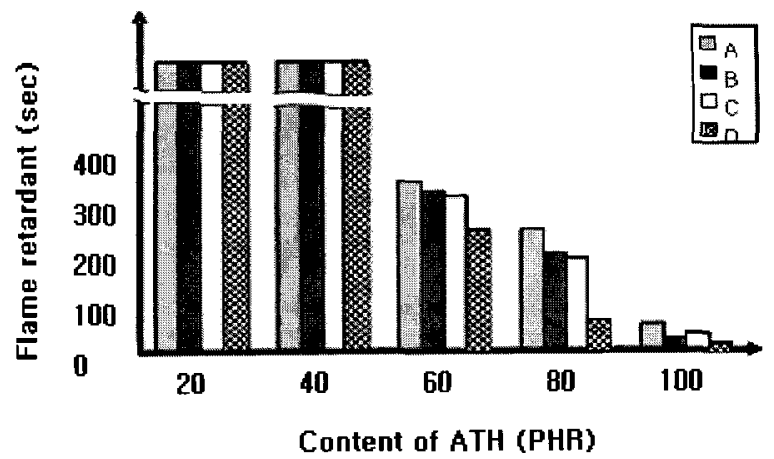

Fig. 8. Flame retardant of silicone compounds according to ATH treatment(A: Non treated, B: acryl silane, C: stearic acid, D: vinyl silane).

The influences of surface treatment of ATH on the physical characteristics, electrical properties, and tracking performance of silicone rubber for high voltage insulators and the followings have been investigated and the followings are concluded.

1. As base polymer, $\alpha, \omega$ - vinyl poly (dimethylmethylphenyl) siloxane(VPMPS) containing dimethyl siloxane and methylphenyl siloxane was successfully prepared by the equilibrium polymerization. Also high voltage silicone rubber composites(HVSRC) were compounded from VPMPS, nano-silica, and ATH modified by various coupling agents.

2. ATH treated with vinyl silane gave increase in bound rubber content and cross-linking density due to the vinyl groups introduced on the surface of ATH which enhance chemical interactions and lead to an increase in crosslinking density.

3. Vinyl silane coupling agents increased hardness, tensile strength, tracking performance, and modulus of HVSRC, and stearic acid decreased the hardness, electric properties, and modulus of HVSRC. This is probably due to the fact that vinyl silane coupling agents contains an active group $\left(-\mathrm{CH}=\mathrm{CH}_{2}\right)$ which is missing in stearic acid.

4. Flame retardant characteristic by ATH surface treatment was not influenced greatly by the kind of ATH surface agents. The flame retardant, dielectric strength, and volumes resistivity of HVSRC filled ATH treated with vinyl silane was by far the best. The high voltage silicone rubber composites(HVSRC) having high mechanical properties, good tracking properties, and good electrical properties were prepared from compounding of VPMPS, nano-silica, and ATH modified by vinyl silane. 


\section{REFERENCES}

[1] W. Lynch, Handbook of Silicone Rubber Fabrication, Litton Educational Publishing Inc., p. 1, 1978.

[2] S. Kobayashi and Yahagi, "Thermally stimulated current in elongated low density polyethylene films", J. Appl. Phys., Vol. 18, p. 261, 1979.

[3] J. Turnhout, "Thermally stimulated discharge of polymer electrets", Polym. J., Vol. 2, p. 173, 1971.

[4] M. F. Lewis, "The science and technology of silicone rubber", Rubber Chemistry and Technology, Vol. XXXV, p. 5, 1962.

[5] J. M. Zeigler and F. W. Gordon Fearon, SiliconBased Polymer Science A Comprehensive Resource, American Chemical Society, Washington, p. 47, 1990.

[6] J. E. McGrath, J. S. Riffle, L. Yilger, and A. K. Banthia, ACS. Symp. Ser., No. 211, Chap. 2, 1983.

[7] W. Reddish, "The dielectric properties of polyethylene terephthalate", Trans. Faraday. Soc., Vol. 46, p. 495, 1950.

[8] A. Toureile and J. P. Reboul, "High-field conduction phenomena in polymers", Ann. Soc. Sci. Bruxelles, Vol. 89, p. 190, 1975.

[9] K. S. Cole and R. H. Cole, "Dispersion and absorp- tion in dielectrics", J. Chem. Phys., Vol. 9, p. 341, 1941.

[10] T. Umemura, T. Kashiwaxaki, and T. Suzuki, "Impurity effect on dielectric properties of polypropylene", Jpn. J. Appl. Phys., Vol. 194, p. $769,1980$.

[11] P. Paul and C. N. Reddy, "Breakdown characteristics of solid dielectrics immersed in high pressure gaseous media and subjected to direct voltage with ripple", IEEE Trans. on Electrical Insulation, Vol. EI-15, p. 43, 1980.

[12] J. E. McGrath, J. S. Riffle, L. Yilgor, and A. K. Banthia, ACS. Symp. Ser., No. 211, Chap. 2, 1983.

[13] UL Standard 94, "Test for Flammability of Plastic Materials for Parts in Devices and Appliances", 4'th edition, 1984.

[14] IEC 60587, "Test Methods for Evaluating Resistance to Tracking and Erosion of Electrical Insulating Materials used Severe Ambient Conditions", 1984.

[15] Wu. J. H., Huang J. L., and Chen N. S., "Study on bound rubber in rubber filled with modified ultrafine mineral powder", Rubb. Chem. Technol., Vol. 73, p. 1, 2000.

[16] Wu. J. H., Z. Shen, C. Wei, Y. Chen, and D. Hu, "Interactions between surface treated ultrafine mineral filled and silicone rubber matrix", Polymers \& Polymer Composites, Vol. 9, No. 3, p. 169, 2001. 